\title{
Design of a Fuel Sensor Noise Reduction System Using Kalman Filter
}

\author{
Rico Bernando Putra ${ }^{1 *)}$ and Suhartati Agoes ${ }^{2)}$ \\ ${ }^{1,2)}$ Department of Electrical Engineering, Trisakti University, Indonesia. \\ Corresponding Email: *) ricobernando25@gmail.com
}

\begin{abstract}
In the field of transportation, telematics is used to obtain vehicle information using Global Positioning System (GPS) technology which is integrated with sensors so that vehicle information can be monitored. One of them is fuel monitoring. The fuel sensor has good accuracy in stationary conditions, but the tability of the data is disturbed when the vehicle is running on an uneven road and causes the tank to shake. This study discusses a fuel sensor noise reduction system using a Kalman filter to overcome the problem of data instability due to shocks. This research aims to reduce noise so that the filter results are closer to the actual result. Filtering is done by changing the process error covariance $(Q)$ and measurement error $(R)$ in the Kalman filter. The fuel sensor noise is simulated using a simulator tank driven by an actuator that can tilt towards the $x$-axis and the $y$-axis to resemble the behavior of a vehicle. The fuel level data from the sensor readings are sent by GPS via the cellular network to a server which is then filtered using a web application. From the test results obtained the best filter with $(Q)$ equals $0.1^{\wedge} 3$ and $(R)$ equals $0.1^{\wedge} 3$. The average error of the best filter results is $4.73 \%$ where this value is $1.92 \%$ smaller than the average error of sensor data before filtering, which is $6.65 \%$. Therefore, this proves that the system can reduce noise that occurs in the fuel sensor with the Kalman filter.
\end{abstract}

Keywords: Fuel sensor, Kalman filter, noise, covariance $Q$, covariance R. Covariance $R$.

\section{INTRODUCTION}

In general, the term telematics is used for the Global Positioning System (GPS) which is a system that functions to show the location of an object on the earth's surface using the help of satellite signal synchronization as an integral part of mobile communication technology or Mobile Communication Technology (MCT). More specifically, the term telematics is used for the field of vehicles and traffic [14].

Currently, the need for a telematics system to find vehicle information has become an important requirement for users, especially for companies that need a transporter fleet to distribute products to support company utilities. In principle, MCT can be built by combining GPS technology and Global System Mobile (GSM) to produce a telematics system that can transmit information wirelessly. GPS data is a set of codes that cannot be read and seen directly by human language, so it needs to be translated first. To make it easy to read, GPS data can be presented visually and can also be developed into a webbased application so that users can access tracking applications anytime and anywhere [1]. Apart from the location of the object or vehicle, other information from the vehicle is also needed by the user to support the utility, one of which is fuel monitoring

Generally, vehicles are equipped with digital or analog indicators to indicate the volume of fuel using a float sensor or Fuel Gauge. In automotive and aviation Fuel Gauge is an instrument used to show the amount of fuel in the fuel tank. Fuel Gauge is in principle a variable resistor that has a resolution that is not too large so that generally the Fuel Gauge cannot show the number of liters with precision. There are several types of sensors that can be used in measuring the fuel sensor, including [2] measuring the level of fuel in the oil tank. using the PINGbased ultrasonic proximity sensor Arduino. The data information obtained will be displayed via SMS. However, the results obtained on the measurement accuracy value will decrease at the fuel height above 25 $\mathrm{cm}$. Furthermore, [3] conducted a fuel volume monitoring system using a universal fuel sender sensor, and the output would be processed by a microcontroller. Meanwhile, [4] designed a fuel measurement system using a low current sensor breakout (LCSB) on traffic characteristics

Some of the studies mentioned above have a weakness, namely the sensitivity level of the sensor's accuracy which is easily affected by external objects because the installation is only attached to the bottom of the tank. Another study that has been conducted by [5] is using a capacitive sensor type in measuring the volume of liquid in the case of the milk beverage industry using the gravimetric method. The capacitive type fuel sensor is in the form of a wand and will be installed directly into the tank so that this capacitive type stick sensor can be the right choice because the sensor takes a direct reading of the liquid which is measured by a certain dielectric constant. Generally, the capacitive type wand fuel sensor has a good level of accuracy on a fixed tank or a stationary storage tank.

However, it is different when the fuel sensor is attached to a vehicle. The stability of the reading of the fuel level data is certainly not a problem when the vehicle is not moving, but the stability of the data can be disturbed when 
the vehicle is running on terrain with uneven or damaged road contours which results in shocks which can be said to be noise. This problem of instability in fuel level data cannot be solved by simply calculating the average because in principle the fuel decreases along with the use of the fuel itself in the vehicle engine. Therefore, we need a method that can predict the actual fuel level conditions so that the deviation from the sensor readings can be minimized.

One of the possible digital filters to be applied to this problem is the Kalman filter. [6] and [7] utilize Discrete Kalman filters to predict wind speed and air temperature. Because the Kalman filter has the advantage of being able to predict a condition based on limited data. Researcher [8] conducted IMU-based Quadrotor navigation with a Kalman Tunning filter, the results obtained have a good level of accuracy. However, this application is tested offline. Meanwhile, [9] uses a Kalman filter to measure fuel based on the available signal through the DBD-II interface. However, the functionality of the estimation algorithm depends on the type of powertrain used.

For this reason, the researcher tries to apply the webbased Kalman filter to solve the problems that occur in the previous explanation. Referring to the need for a telematics system, a GPS tracking device is used which is used to read sensor data and transmit it to the server. With a noise reduction system that uses a web-based Kalman filter, it is hoped that the instability of this fuel data can be overcome and the reading of the fuel data will be more accurate because it is displayed in real-time.

\section{Methodology}

This study aims to design a noise reduction system using a Kalman filter for fuel sensor applications. The whole system block diagram can be seen from Figure 1 below:

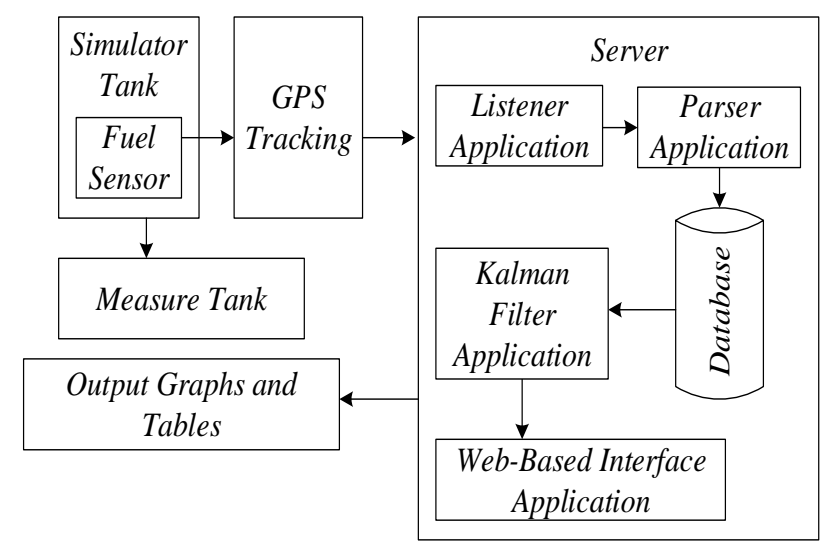

Figure 1. Block diagram system

Based on the block diagram image above, the system is divided into 4 main parts, namely the simulator tank, measuring tank, GPS tracking device, and server with a design method that includes hardware design and software design.

\section{A. Hardware Design}

The hardware design of the fuel sensor noise reduction system using the Kalman filter can be explained in the following stages:

\section{1) Simulator Tank}

The simulator tank as shown in Figure 2 is a tank that is used as a simulation tank. In this tank, a fuel sensor is attached which is used to read the volume of fuel in the tank. In this tank, an actuator system is also added which functions to generate shocks, which is assumed to be a vehicle tank that experiences shocks when walking on uneven, bumpy, or perforated road contours. This simulator tank is filled with diesel fuel which is then flowed to the measuring tank. This fuel delivery process is assumed to be fuel consumption.

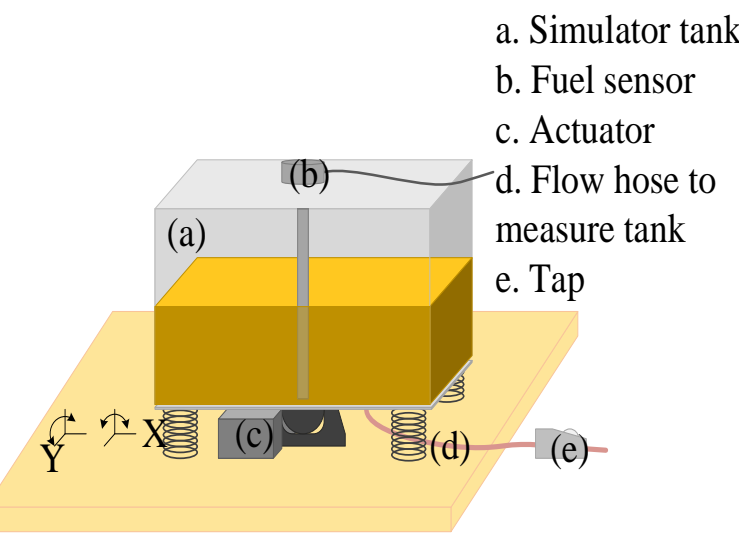

Figure 2. Simulator tank

\section{2) Measure Tank}

Because the simulator tank is conditioned to experience shocks generated by the actuator so that measurements are not possible, a measuring tank is designed as shown in Figure 3 as a measurement reference. In the measuring tank, a liter measuring unit is made, so that the volume of fuel in the simulator tank can be calculated by calculating the simulator tank capacity minus the volume of fuel filled in the measuring tank.

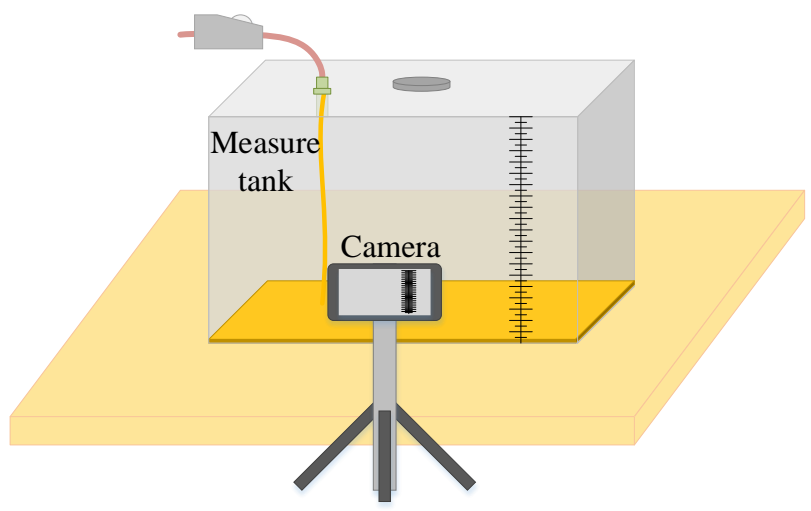

Figure 3. Measure tank 
In the measuring tank, there is a timer module that functions to regulate sensor readings and camera image taking of measurement results can be done simultaneously. The timer module triggers the GPS device via digital input to send data to the server and at the same time, the timer module triggers the camera to take a picture of the fuel volume level.

\section{3) GPS Tracking Device}

The GPS tracking device used as shown in Figure 4 is equipped with an analog input and a digital input [10]. The fuel sensor is connected to the analog input of the GPS tracking device because the fuel sensor used has an analog output type of 0 - 5 volts [11]. The fuel sensor used with the capacitive type is in the form of a stick or stick, where the sensor meets the standard of use in the automotive and industrial fields

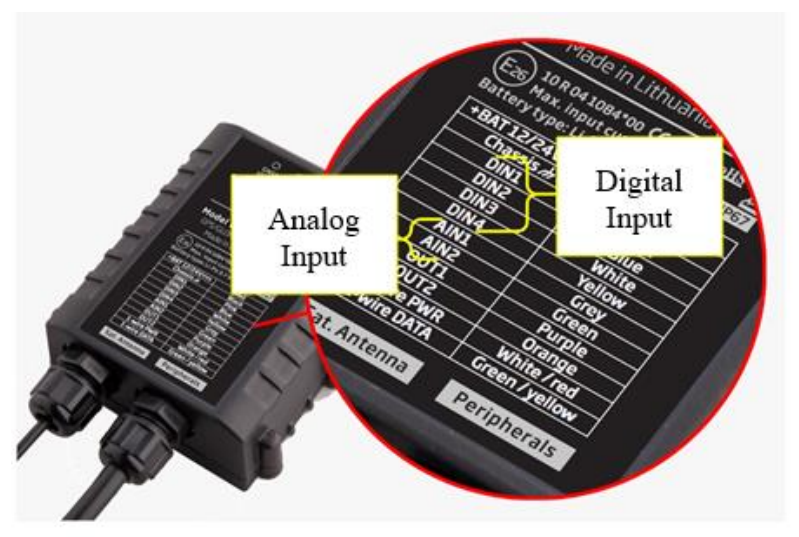

Figure 4. GPS tracking device

The parameters contained in the GPS device are time, coordinates including latitude, longitude, altitude, direction, and input-output data including fuel sensor data connected via the analog input. This GPS device also functions as a medium for transmitting data to the server. Before sending data from several parameters, it is combined into one data packet.

\section{4) Central Processing Server}

In this study, the Raspberry device was used Pi 3 as shown in Figure 5 which functions as a central processing server that has several applications in it, namely the Listener application which functions to receive and parse data packages from GPS, the Parser application which functions to distribute GPS data to the database, the Kalman filter application which functions to handle requests user to perform the filter process, as well as a web-based interface application that can be accessed anywhere in charge of displaying the filter output data in tables and graphics. The choice of this device is because the Raspberry Pi has small dimensions and power consumption, as well as an affordable price.

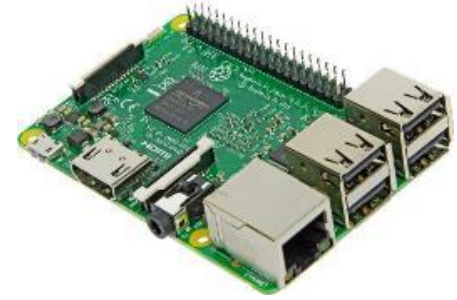

Figure 5. Raspberry Pi as a server

\section{B. Software Design}

In this study, there were 4 applications made, namely a listener application, a parser application, a Kalman filter application, and a web-based interface application.

\section{1) Listener Application}

Is an application that is tasked with receiving data packets from a GPS tracking device with a certain protocol in hexadecimal form. In addition to receiving data, this listener application is also tasked with parsing data packets so that the data can be translated and recognized into human language. This listener application is programmed using the Python programming language.

\section{2) Parser Application}

The parser application is in charge of distributing data that has been parsed by the listener application which is then stored in a table on the database with the MariaDB server.

\section{3) Aplikasi Filter Kalman}

The Kalman filter has two main phases, namely prediction, and update. The prediction phase uses the state estimate results from the previous timing to produce an estimate of the state at the current time. In the update phase, the measurement result information at the time of the previous timing is used to provide prediction results for the current timing. These two phases are carried out repeatedly to form a cycle [12]. The prediction phase equation can be seen in the following equation:

$$
\begin{aligned}
& \hat{x}_{\bar{k}}=A \hat{x}_{k-1}+B u_{k} \\
& P_{\bar{k}}=A P_{k-1} A^{T}+Q
\end{aligned}
$$

While the update phase equation is as follows:

$$
\begin{aligned}
& K_{k}=P_{\bar{k}} H^{T}\left(H P_{\bar{k}} H^{T}+R\right)^{-1} \\
& \hat{x}_{k}=\hat{x}_{\bar{k}}+K_{k}\left(z_{k}-H \hat{x}_{\bar{k}}\right) \\
& P_{k}=\left(I-K_{k} H\right) P_{\bar{k}}
\end{aligned}
$$

$\hat{x}_{\bar{k}} \quad$ is a priori estimate of the previous state or condition for time step $\mathrm{k}$, which is obtained by multiplying the filter parameter A which is a matrix that connects the previous and present time states with $\mathrm{x}_{-}(\mathrm{k}-1)$, which is the posterior estimate of the state or the next condition for time step $\mathrm{k}-1$. The result is then added with the filter parameter B which is a matrix that connects the control signal or input with the current state multiplied by the control input u_k. $\mathrm{P}_{-} \mathrm{k}^{-}$is the priority covariance estimate error, while $\mathrm{P}_{-}$ $(\mathrm{k}-1)$ is the posterior estimate error covariance. In practice, the process noise covariance $Q$ and measurement noise covariance $\mathrm{R}$ can change with each time step or each measurement. $\mathrm{K} \_\mathrm{k}$ is the 
Kalman gain and $\mathrm{z} \_\mathrm{k}$ is the actual measurement. $\mathrm{H}$ is a matrix that connects the current state of time with the measurement results. The final result of Kalman filter estimation is $\mathrm{x}_{-} \mathrm{k}$ [13].

This study aims to filter the fuel sensor voltage contaminated with noise with the state transition equation as follows:

$$
V_{\bar{n}}=V_{n-1}+w_{n}
$$

Where $\mathrm{V} \_n$ is the current-voltage, $\mathrm{V}_{-}$(n-1) is the last voltage, and $\mathrm{w} \_\mathrm{n}$ is random noise.

The next step is to prepare the Kalman filter input and constant. This study uses a fixed variable, namely the fuel sensor voltage so that all matrices are assigned a $1 \times 1$ matrix.

In equations (1) and (2) there is a matrix A which needs to be multiplied by the last state to get the newest state. Since this is a single voltage mixed with noise (6), matrix $\mathrm{A}$ is set to 1 .

$$
V_{\bar{n}}=V_{n-1} \rightarrow A=[1]
$$

Because the voltage is obtained directly, the matrix $\mathrm{H}$ is defined as 1 . The object in this study is a constant voltage and no input in the model can be changed to affect anything so that the matrix B is set to 0 [15]. From the above steps, the Kalman filter design is obtained as follows:

$$
\begin{aligned}
\hat{x}_{\bar{k}} & =\hat{x}_{k-1} \\
P_{\bar{k}} & =P_{k-1}+Q \\
K_{k} & =P_{\bar{k}}\left(P_{\bar{k}}+R\right)^{-1} \\
\hat{x}_{k} & =\hat{x}_{\bar{k}}+K_{k}\left(z_{k}-\hat{x}_{\bar{k}}\right) \\
P_{k} & =\left(I-K_{k}\right) P_{\bar{k}}
\end{aligned}
$$

Based on equations (8), (9), (10), (11), and (12), the Kalman filter function can be arranged in the Python programming language as shown in Figure 6 below:

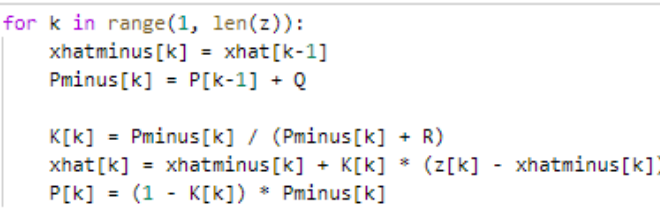

Figure 6. Kalman filter in python programming

From Figure 6 above, it can be explained that line 20 is a repetition function which is a cycle of the predictive phase and the update phase. Lines 21 and 22 are predictive phases that are arranged according to equations (8) and (9). Furthermore, based on equations (10), (11), and (12), functions can be arranged in a programming language as shown in lines 24, 25, and 26.

\section{4) Interface Application}

The interface application is designed with the webbased PHP and Javascript programming languages so that this application can be accessed from anywhere and anytime via a browser on a computer or smartphone.

\section{RESULTS AND DISCUSSION}

Based on the design that has been done, a fuel sensor noise reduction system test tool is produced using a
Kalman filter as shown in Figure 7 below.

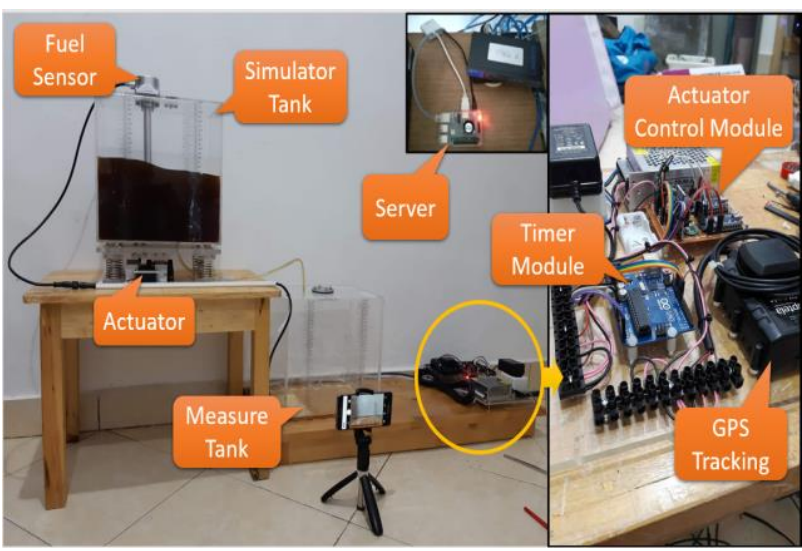

Figure 7. Noise reduction system test equipment

From the test, the original data of the fuel sensor and the actual data of the measurement results were obtained as shown in Figure 8 below:

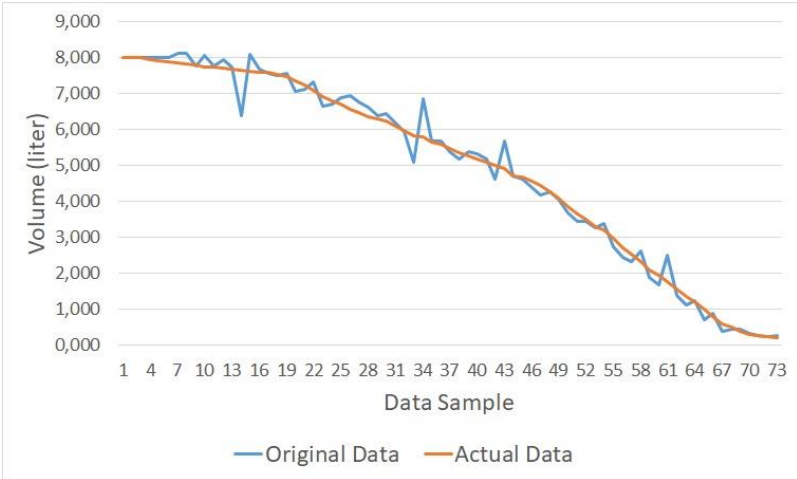

Figure 8. Measurement data and sensor original data.

From the calculation, it is known that the average error that occurs due to noise is $6.65 \%$. The average error percentage of the original sensor data is then used as a reference for the success of the noise reduction system on the condition that the average error percentage of the filter results must be less than the average error percentage of the original sensor data.

The filtration test method is carried out by adjusting the variance value of the $Q$ process error and the variance of the measurement error $\mathrm{R}$ with calculations based on equations (8), (9), (10), (11), and (12). In this study, measurements were made for a fuel sensor with a constant reading interval of sensor data per 1 minute so that it was assumed that no errors occurred in the process. so that $\mathrm{Q}$ is assumed to be very small close to 0 . Q can be set to 0 , but for the Kalman filter tunning process to produce a flexible output, $\mathrm{Q}$ is set which is very small but not zero, namely equals $0.1^{\wedge} 3$.

The test results obtained with the variance value of the Q process error of (0.1) 3 and the variance value of the measurement error R of (0.1) 3 can be shown in Figure 9 below: 


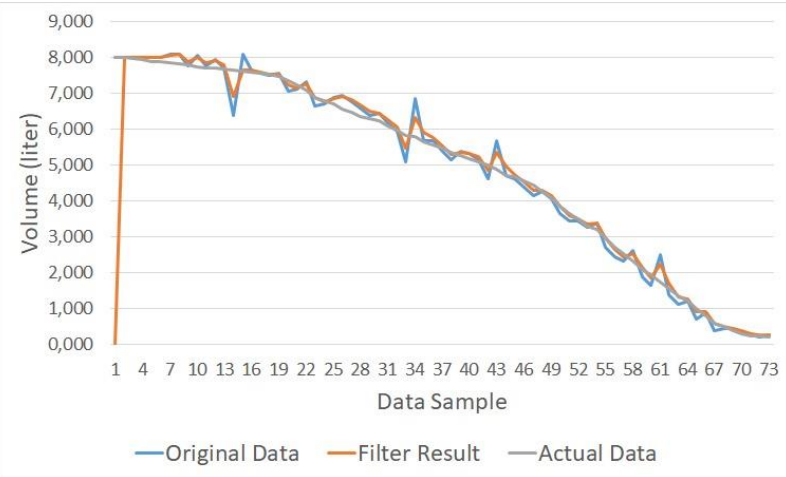

Figure 9. Results filter wiht $Q=(0.1)^{3}$ dan $R=(0.1)^{3}$

From the graph shown in Figure 10 above, it can be explained that the $\mathrm{P}_{-} \mathrm{k}$ value previously initialized with the value 1 converges rapidly and is constant at 0.0006 . This indicates that the estimation results obtained have a high level of confidence. To find out the level of accuracy of the filter, the error calculation is carried out with the calculation results as shown in Table 1 below:

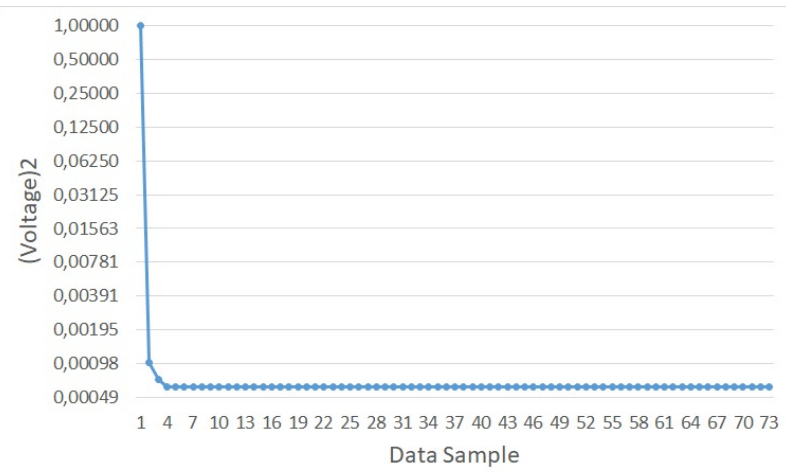

Figure 10. Covariance error graph

From the graph shown in Figure 10 above, it can be explained that the $\mathrm{P}_{-} \mathrm{k}$ value previously initialized with the value 1 converges rapidly and is constant at 0.0006 . This indicates that the estimation results obtained have a high level of confidence. To find out the level of accuracy of the filter, the error calculation is carried out with the calculation results as shown in Table 1 below:

Tabel 1. Error Calculation with Q $(0.1)^{3}$ dan $\mathrm{R}(0.1)^{3}$

\begin{tabular}{ccccccc}
\hline \multirow{2}{*}{$\begin{array}{c}\text { No } \\
\text { Original Filter }\end{array}$} & $\begin{array}{c}\text { Actual } \\
\text { Data } \\
\text { (liter) }\end{array}$ & $\begin{array}{c}\text { Result } \\
\text { (liter) }\end{array}$ & $\begin{array}{c}\text { Eata } \\
\text { (liter) }\end{array}$ & $\begin{array}{c}\text { Measurement } \\
\text { with Original } \\
\text { Data }\end{array}$ & $\begin{array}{c}\text { Measurement } \\
\text { with Filter } \\
\text { Result }\end{array}$ \\
\hline 1 & 8,000 & 0,000 & 8,000 & 0,000 & 0,000 \\
\hline 2 & 8,000 & 7,991 & 7,995 & 0,063 & 0,050 \\
\hline 3 & 8,000 & 7,997 & 7,990 & 0,125 & 0,088 \\
\hline 4 & 8,000 & 7,997 & 7,950 & 0,629 & 0,591 \\
\hline 5 & 7,994 & 7,994 & 7,900 & 1,190 & 1,190 \\
\hline 6 & 7,994 & 7,994 & 7,890 & 1,318 & 1,318 \\
\hline 7 & 8,107 & 8,063 & 7,850 & 3,274 & 2,713 \\
\hline
\end{tabular}

\begin{tabular}{|c|c|c|c|c|c|}
\hline 8 & 8,107 & 8,088 & 7,825 & 3,604 & 3,361 \\
\hline 9 & 7,774 & 7,893 & 7,800 & 0,333 & 1,192 \\
\hline 10 & 8,050 & 7,991 & 7,750 & 3,871 & 3,110 \\
\hline 11 & 7,780 & 7,859 & 7,725 & 0,712 & 1,735 \\
\hline 12 & 7,943 & 7,909 & 7,700 & 3,156 & 2,714 \\
\hline 13 & 7,724 & 7,793 & 7,675 & 0,638 & 1,537 \\
\hline 14 & 6,379 & 6,918 & 7,650 & 16,614 & 9,569 \\
\hline 15 & 8,097 & 7,646 & 7,625 & 6,190 & 0,275 \\
\hline 16 & 7,664 & 7,655 & 7,600 & 0,842 & 0,724 \\
\hline 17 & 7,558 & 7,595 & 7,575 & 0,224 & 0,264 \\
\hline 18 & 7,501 & 7,536 & 7,525 & 0,319 & 0,146 \\
\hline 19 & 7,551 & 7,545 & 7,475 & 1,017 & 0,936 \\
\hline 20 & 7,050 & 7,238 & 7,350 & 4,082 & 1,524 \\
\hline 21 & 7,112 & 7,159 & 7,250 & 1,903 & 1,255 \\
\hline 22 & 7,335 & 7,266 & 7,100 & 3,310 & 2,338 \\
\hline 23 & 6,661 & 6,893 & 6,900 & 3,464 & 0,101 \\
\hline 24 & 6,717 & 6,783 & 6,800 & 1,221 & 0,250 \\
\hline 25 & 6,890 & 6,849 & 6,700 & 2,836 & 2,224 \\
\hline 26 & 6,943 & 6,905 & 6,550 & 6,000 & 5,420 \\
\hline 27 & 6,777 & 6,824 & 6,475 & 4,664 & 5,390 \\
\hline 28 & 6,604 & 6,689 & 6,350 & 4,000 & 5,339 \\
\hline 29 & 6,388 & 6,501 & 6,290 & 1,558 & 3,355 \\
\hline 30 & 6,438 & 6,460 & 6,250 & 3,008 & 3,360 \\
\hline 31 & 6,169 & 6,278 & 6,100 & 1,131 & 2,918 \\
\hline 32 & 5,946 & 6,071 & 5,975 & 0,485 & 1,607 \\
\hline 33 & 5,099 & 5,469 & 5,825 & 12,464 & 6,112 \\
\hline 34 & 6,868 & 6,332 & 5,800 & 18,414 & 9,172 \\
\hline 35 & 5,667 & 5,921 & 5,650 & 0,301 & 4,796 \\
\hline 36 & 5,667 & 5,764 & 5,575 & 1,650 & 3,390 \\
\hline 37 & 5,385 & 5,529 & 5,475 & 1,644 & 0,986 \\
\hline 38 & 5,165 & 5,303 & 5,350 & 3,458 & 0,879 \\
\hline 39 & 5,385 & 5,353 & 5,275 & 2,085 & 1,479 \\
\hline 40 & 5,328 & 5,337 & 5,175 & 2,957 & 3,130 \\
\hline 41 & 5,165 & 5,231 & 5,100 & 1,275 & 2,569 \\
\hline 42 & 4,610 & 4,845 & 5,000 & 7,800 & 3,100 \\
\hline 43 & 5,689 & 5,366 & 4,900 & 16,102 & 9,510 \\
\hline 44 & 4,720 & 4,964 & 4,700 & 0,426 & 5,617 \\
\hline 45 & 4,607 & 4,742 & 4,675 & 1,455 & 1,433 \\
\hline 46 & 4,387 & 4,522 & 4,550 & 3,582 & 0,615 \\
\hline 47 & 4,165 & 4,299 & 4,450 & 6,404 & 3,393 \\
\hline 48 & 4,278 & 4,284 & 4,275 & 0,070 & 0,211 \\
\hline 49 & 4,052 & 4,140 & 4,100 & 1,171 & 0,976 \\
\hline 50 & 3,663 & 3,845 & 3,850 & 4,857 & 0,130 \\
\hline
\end{tabular}




\begin{tabular}{|c|c|c|c|c|c|}
\hline 51 & 3,443 & 3,597 & 3,650 & 5,671 & 1,452 \\
\hline 52 & 3,443 & 3,500 & 3,500 & 1,629 & 0,000 \\
\hline 53 & 3,274 & 3,359 & 3,300 & 0,788 & 1,788 \\
\hline 54 & 3,387 & 3,374 & 3,200 & 5,844 & 5,438 \\
\hline 55 & 2,722 & 2,970 & 2,975 & 8,504 & 0,168 \\
\hline 56 & 2,443 & 2,644 & 2,700 & 9,519 & 2,074 \\
\hline 57 & 2,330 & 2,449 & 2,525 & 7,723 & 3,010 \\
\hline 58 & 2,609 & 2,546 & 2,325 & 12,215 & 9,505 \\
\hline 59 & 1,885 & 2,136 & 2,100 & 10,238 & 1,714 \\
\hline 60 & 1,662 & 1,844 & 1,950 & 14,769 & 5,436 \\
\hline 61 & 2,499 & 2,249 & 1,750 & 42,800 & 28,514 \\
\hline 62 & 1,386 & 1,715 & 1,550 & 10,581 & 10,645 \\
\hline 63 & 1,107 & 1,339 & 1,350 & 18,000 & 0,815 \\
\hline 64 & 1,220 & 1,264 & 1,200 & 1,667 & 5,333 \\
\hline 65 & 0,718 & 0,925 & 1,000 & 28,200 & 7,500 \\
\hline 66 & 0,887 & 0,900 & 0,800 & 10,875 & 12,500 \\
\hline 67 & 0,386 & 0,580 & 0,600 & 35,667 & 3,333 \\
\hline 68 & 0,442 & 0,495 & 0,500 & 11,600 & 1,000 \\
\hline 69 & 0,439 & 0,458 & 0,375 & 17,067 & 22,133 \\
\hline 70 & 0,329 & 0,379 & 0,300 & 9,667 & 26,333 \\
\hline 71 & 0,273 & 0,310 & 0,250 & 9,200 & 24,000 \\
\hline 72 & 0,220 & 0,254 & 0,225 & 2,222 & 12,889 \\
\hline 73 & 0,273 & 0,263 & 0,200 & 36,500 & 31,500 \\
\hline
\end{tabular}

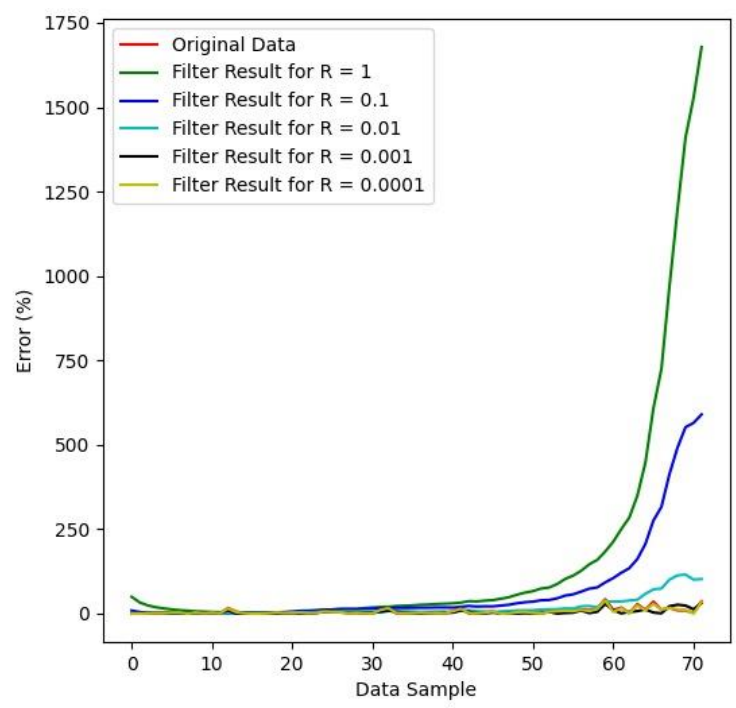

Figure 11. Graph of comparison of errors for each test

Tabel 2. Comparison of Errors for Each Test

\begin{tabular}{ccccccccc}
\hline \multirow{2}{*}{ No } & & & \multicolumn{2}{c}{$\begin{array}{c}\text { Average Error } \\
(\mathbf{\%})\end{array}$} & $\begin{array}{c}\text { Smallest Error } \\
(\boldsymbol{\%})\end{array}$ & \multicolumn{2}{c}{ Large Error (\%) } \\
\cline { 3 - 9 } & & $\begin{array}{c}\text { Original Filter } \\
\text { Data }\end{array}$ & $\begin{array}{c}\text { Original } \\
\text { Result }\end{array}$ & $\begin{array}{c}\text { Filter } \\
\text { Asli }\end{array}$ & $\begin{array}{c}\text { Original } \\
\text { Result }\end{array}$ & $\begin{array}{c}\text { Filter } \\
\text { Data }\end{array}$ & Result \\
\hline 1 & 1 & 6,65 & 163,68 & 0,06 & 0,31 & 42,80 & 1678,00 \\
\hline 2 & $(0,1)^{1}$ & 6,65 & 70,62 & 0,06 & 0,55 & 42,80 & 590,00 \\
\hline 3 & $(0,1)^{2}$ & 6,65 & 17,93 & 0,06 & 0,18 & 42,80 & 115,60 \\
\hline 4 & $(0,1)^{3}$ & 6,65 & 4,73 & 0,06 & 0,00 & 42,80 & 31,50 \\
\hline 5 & $(0,1)^{4}$ & 6,65 & 6,04 & 0,06 & 0,03 & 42,80 & 38,91 \\
\hline
\end{tabular}

From the results of the error calculation, as shown in Table 1 above, it can be seen that the percentage of errors that occur in each average estimate is smaller than the error that occurs in the original sensor data. The calculation of the average error obtained is $4.73 \%$, which means that the percentage of errors that occur in the filter results is smaller than the errors that occur before the filtering.

From several tests that have been carried out, it can be compared the error against the actual data that occurs at each change in the measurement error $\mathrm{R}$ with the $\mathrm{Q}$ process error variant set at (0.1) 3 as shown in Figure 11 below.

From the graph shown in Figure 11 above, it can be seen that by adjusting the large value of the $\mathrm{R}$ variant, the system will increasingly distrust the original sensor data so that the difference between the filter results and the actual data becomes large. Conversely, by reducing the value of variant $\mathrm{R}$, the error rate will also be smaller. It can also be seen that the minimum and maximum errors that occur in each filter estimate are as shown in Table 2 below:

From Table 2 above, it can be seen that the best filter parameter setting is to set the variance value of the measurement error $\mathrm{R}$ of (0.1) 3 and the variant of the $\mathrm{Q}$ process error of (0.1) 3 with the percentage error of the filter results obtained, namely $4.73 \%$. It can also be seen that before filtering, the biggest error in the original sensor data was $42.8 \%$ and after filtering with the $Q$ variant of (0.1) 3 and the R variant of $(0.1) 3$, the biggest error that occurred decreased $11.3 \%$ to $31,5 \%$ proves that the filter is able to reduce fuel sensor read errors.

\section{CONCLUSION}

This study discusses the fuel sensor noise reduction system with a Kalman filter. The system is expected to solve the problem of data instability due to shocks. Noise reduction is done in order to obtain a filter that is close to the true value. This noise reduction system consists of 4 main parts, namely the simulator tank, measuring tank, GPS tracking device and server. Furthermore, the test method is carried out by changing the process error covariance $(\mathrm{Q})$ and measurement error $(\mathrm{R})$ in the Kalman filter. Fuel sensor noise is simulated using a simulator tank driven by an actuator. Then the fuel level data from the sensor readings is sent by the GPS via the cellular 
network to the server which is then filtered using a web application.

Based on the research results, it is obtained the best filter value that has a fast response with the closest estimation results to the actual. This value depends on the value of the variance of the process error (Q) and the measurement error $(\mathrm{R})$. Then the two variance values of the process error $(\mathrm{Q})$ and the measurement error $(\mathrm{R})$ must be determined appropriately

The test results show that the best (Q) and (R) values of the Kalman filter are with a process error variant value of (0.1) 3 and a measurement error of (0.1) 3. This is evidenced by the smallest average error of several tests, namely $4.73 \%$. The best filter results obtained were $4.73 \%$ with a difference of $1.92 \%$ smaller than the original fuel sensor data before filtering, namely $6.65 \%$. This value means that the system created is capable reduce noise that occurs on the fuel sensor.

\section{ACKNOWLEDGEMENT}

On this occasion, the authors would like to thank my colleagues in the Electrical Engineering Masters study program who also provided support so that this research could be carried out.

\section{REFERENCES}

[1] Bernard, "Perancangan Server Penerima Data dari Perangkat Pelacak Kendaraan dengan Teknologi GPS dan GPRS Berbasis Perl," Skripsi, Teknik Elektro, Universitas Trisakti, Jakarta, 2015.

[2] D.Y. Sukma, E. Safrianti, and C. Idrus, "Teknologi Informasi Dan Otomatisasi Tangki Minyak Berbasis Arduino Uno," pp. 101-106, 2019.

[3] M. Nasir and M.A. Mudhoffar, "Perancangan Sistem Monitoring Volume Bahan Bakar Pada Prototype Sephull Bubble Vessel," vol. 4, no. 1, pp. 29-34, 2010.

[4] R. Raharjo, "Perancangan Sistem Pengukuran Konsumsi Bahan Bakar Kendaraan Bermotor Berbasis Arduino," pp. 31-35, 2016.

[5] O.N. Milk and B. Industry, "Sistem Pengukuran Volume Cairan Menggunakan Sensor Kapasitif: Studi Kasus Pada Industri Minuman Susu," vol.42. no.2, pp. 115-124, 2019.

[6] I. Fitria, P. Hasanah, and P.S. Matematika, "Penerapan Algoritma Kalman Filter dalam Prediksi Kecepatan Angin di Kota Balikpapan," vol. 1, no. 2, pp. 25-32, 2017.

[7] B.A. Tengger, "Pemanfaatan Metode Kalman Filter Diskrit untuk Menduga Suhu Udara," vol. 1, no. 2, pp. 127-132, 2019.

[8] I. Kolmanovsky, K. Mcdonough, and O. Gusikhin, "Estimation of Fuel Flow for Telematics-Enabled Adaptive Fuel and Time Efficient Vehicle Routing," no. d, pp. 139-144, 2011.

[9] D.T. Elektro, S. Tinggi, and T. Adisutjipto, "Sistem Navigasi Quadrotor Berbasis IMU dengan Kalman Filter Tuning," vol. 11, no. 1, pp. 39-46, 2019.

[10] “FM-Eco4+." https:// www.ruptela.com/product/fm-eco4s/ (accessed Mar. 8, 2020).
[11] S. Joint and T. Co, “JT606X User Manual,” pp. 1-16, 2014.

[12] D. A. Wicaksono, "Rancang Bangun Sistem Navigasi GPS/INS Dan Kompas Digital Dengan Kalman Filter Pada Mikrokontroler AVR," 2009.

[13] H. Soebhakti and R. A. Fatekha, "Implementasi Kalman Filter Pada Sensor Jarak Berbasis Ultrasonik," 1960.

[14] Telematics."https://en.wikipedia.org/wiki/Telematics/ (Accessed Des. 7, 2019).

[15] Kalman Filters for Undergrads Part I: Linear Kalman Filters." http: //greg.czerniak.info /guides /kalman1/ (accessed Des. 7, 2019). 